CASO CLÍNICO

\title{
USO CLÍNICO DEL AGREGADO DE TRIÓXIDO MINERAL (MTA) EN EL TRATAMIENTO DE LESIONES RADICULARES
}

\section{CLINICAL USE OF MINERAL TRIOXIDE AGGREGATE (MTA) IN THE TREATMENT OF RADICULAR LESIONS}

\author{
Guiselle Andrea Verástegui Baldárrago ${ }^{1}$ \\ ${ }^{1}$ Docente de la Facultad de Odontología. Universidad Latinoamericana CIMA
}

\section{RESUMEN}

Las lesiones Periapicales entre ellos las perforaciones radiculares son una complicación indeseada del tratamiento endodóntico que provoca la pérdida de la integridad de la raíz y posterior destrucción del tejido periodontal adyacente. Investigaciones señalan que el Agregado de Trióxido Mineral (MTA) es un excelente material de sellado utilizado en la actualidad en muchas situaciones clínicas como reparación de perforaciones radiculares y regeneración del tejido dental. El presente caso clínico describe el sellado de una perforación radicular utilizando MTA en la pieza 1.2; la cual fue provocada por un anterior tratamiento al colocar un perno colado. Luego se procedió a realizar una apisectomía, tras una lesión periapical ocasionada por una perforación radicular. Algunos de los dientes tratados quirúrgicamente pueden no evolucionar hacia la reparación, por lo tanto, el desafío que afrontamos es la posibilidad de eliminar los factores que puedan afectar el éxito del tratamiento.

Palabras claves: Apisectomía, MTA, perforaciones radiculares, pernos radiculares.

\section{ABSTRACT}

Periapical lesions including root perforations are an unwanted complication of endodontic treatment that results in the loss of root integrity and subsequent destruction of adjacent periodontal tissue. Research indicates that the Mineral Trioxide Aggregate (MTA) is an excellent sealing material currently used in many clinical situations such as repair of root perforations and regeneration of dental tissue. The present clinical case describes the sealing of a radicular perforation using MTA in tooth 1.2; which was caused by a previous treatment when placing a cast post. Then we proceeded to perform an apisectomy, after a periapical lesion caused by a radicular perforation. Some of the teeth treated surgically may not evolve towards repair, therefore, the challenge we face is the possibility of eliminating the factors that may affect the success of the treatment.

Keywords: MTA, Apisectomy, radicular perforation, posts radicular. 


\section{INTRODUCCIÓN}

La perforación radicular es una comunicación artificial entre el sistema del conducto radicular y los tejidos de soporte del diente, con frecuencia es de origen iatrogénico como consecuencia desde la fresa en la conformación del acceso cameral en la localización de la entrada a los conductos radiculares ${ }^{(1)}$.

Muchos materiales se han utilizado para la reparación de éstos como son la gutapercha, la amalgama de plata, el ionómero de vidrio y otros ${ }^{(2)}$. Una vez que el proceso infeccioso se ha establecido por sí mismo en el sitio de la perforación, el pronóstico del tratamiento es desfavorable y las complicaciones pueden conducir a la exodoncia del diente afectado ${ }^{(3)}$.

El agregado de trióxido mineral (MTA) ha sido estudiado ampliamente utilizado como material para sellar las comunicaciones entre el sistema de conductos radiculares y los tejidos perirradiculares. Sus propiedades han sido evaluadas in vitro e in vivo en la bibliografía, pero todavía no existen estudios ni resultados a largo plazo. Lo que sí se sabe es que este material resulta muy prometedor para utilizarse tanto en perforaciones radiculares como en obturaciones retrógradas y en el tratamiento de exposiciones pulpares, gracias a que tiene la cualidad de formar puentes dentinarios, ser biocompatible, $\mathrm{pH}$ alcalino y que no favorece la inflamación ${ }^{(4)}$.

El objetivo de este artículo es reportar un caso clínico donde se hace énfasis en dos tratamiento que requieren un sellado con MTA, en una perforación radicular lateral y una apisectomía, sin implicar un nuevo retratamiento radicular.

\section{CASO CLÍNICO}

Paciente de 35 años de edad, de sexo femenino, acude por recomendación de un paciente a la Clínica de la Especialidad de Periodoncia e Implantología de la Facultad de Ciencias de la Salud de la Universidad Nacional Jorge Basadre Grohmann (Tacna - Perú) en mayo del 2017 por requerir un tratamiento en la pieza 1,2 . Se realizó la historia clínica. Durante la anamnesis, la paciente no refiere antecedentes sistémicos, consumo de tabaco ni patologías que se deba considerar.

Al examen clínico, es una paciente de tez trigueña, con simetría facial, sin lesiones aparentes. Al examen intraoral se observa una restauración defectuosa de la pieza 1,2 con leve inflamación gingival y presencia de fístula a nivel de la encía adherida vestibular (Figura 1), la paciente refiere que aproximadamente un año antes había recibido un tratamiento endodóntico con colocación de perno intrarradicular.

Al examen radiográfico se observó un área radiolúcida compatible con un absceso que afecta la región apical hasta el tercio medio radicular y presentaba una reconstrucción coronal amplio con la colocación de un perno intrarradicular, que se observaba desviado del eje longitudinal de la raíz hacia la cara vestibular del lateral, con lo que se confirmó la presencia de una perforación radicular(Figura 2).

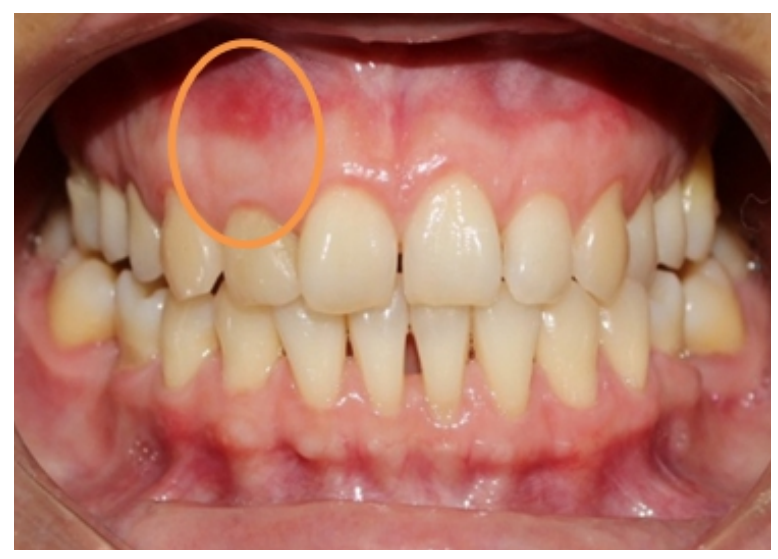

Figura 1. Diagnóstico Clinico. Fistula pza 1.2 Fuente: Elaboración propia

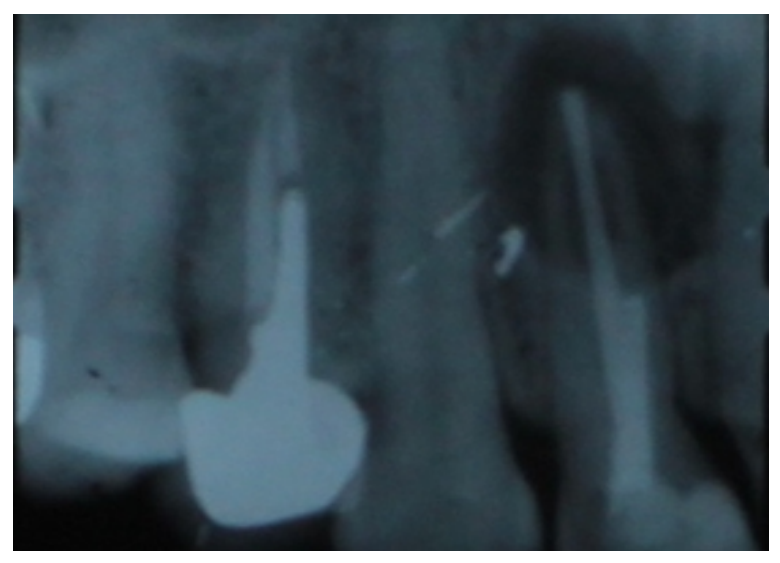

Figura 2. Examen Radiográfico.

Fuente: Elaboración propia.

El paciente fue notificado de las opciones de tratamiento, optando por no querer retirarse el perno por temor a perder la pieza; ante ello, se decidió tratar de ser lo más conservador posible cuidando de mantener la pieza dental en boca el mayor tiempo posible. Luego de firmar el consentimiento informado se procedió a realizar los siguientes tratamientos: FASE 1: sellado de la perforación radicular con MTA a través del abordaje quirúrgico. FASE 2: realizar un curetaje periapical y apisectomía de la pieza 1,2 .FASE 3: obturación retrógrada del conducto apical con MTA. FASE 4: rellenar el defecto óseo con un xenoinjerto recubriéndolo con una membrana de colágeno (regeneración ósea guiada), conservando la pieza dental implicada. 


\section{Procedimiento Quirúrgico}

Previa asepsia de la zona a intervenir, se procedió con la infiltración con anestesia local, lidocaína al $2 \%$ más epinefrina 1:80000 por vestibular y nasopalatino. Para el abordaje quirúrgico se realizó un colgajo tipo semilunar, llegando profundamente al hueso. Al exponer el sitio de la lesión, se encontró que la zona afectada por la perforación involucraba la pared vestibular de la raíz (tercio medio), que no era visible radiográficamente. El defecto óseo se extendía en la superficie vestibular desde el tercio medio radicular hasta la zona apical de la pieza (Figura 3).

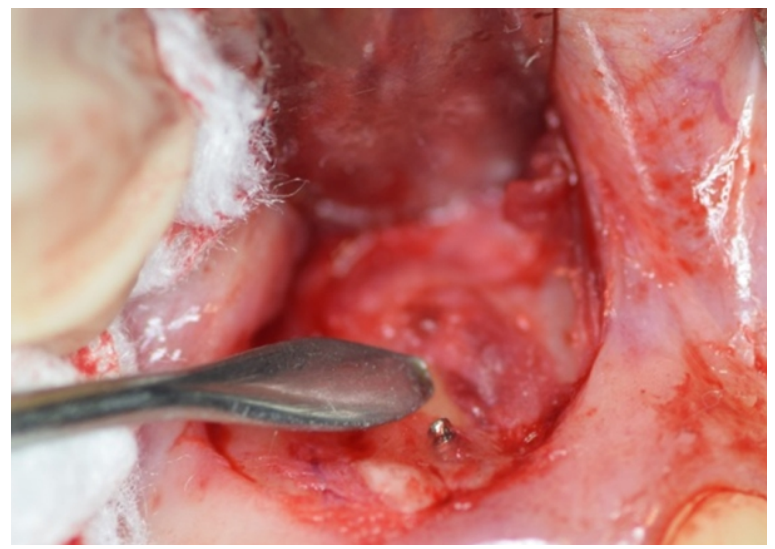

Figura 3. Intervencion Qx. (Incisión y Osteotomía). Perforación radicular por poste metálico

Fuente: Elaboración propia

Se procedió al desgaste con una fresa redonda diamantada en el extremo apical del perno colado que está expuesto y sellamos la región de la perforación con el empleo del MTA(Agregado de Trióxido Mineral).

Se realizó la osteotomía o eliminación del tejido óseo remanente alrededor del ápice dentario y se irrigó constantemente con suero fisiológico. Posteriormente, se realizó un curetaje apical, que tiene como finalidad la eliminación completa del tejido patológico que está alrededor del ápice dentario y al raspado del cemento apical (Figura 4).

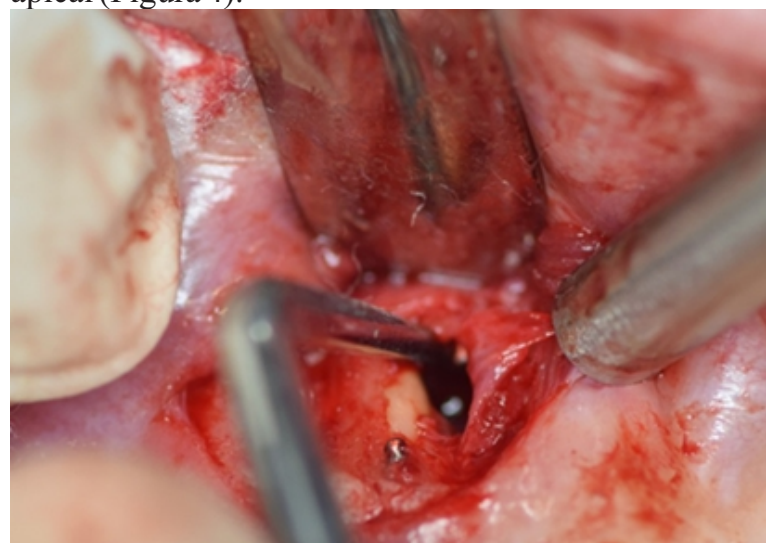

Figura 4. Curetaje apical. Remoción de proceso infeccioso

Fuente: Elaboración propia
Para la sección del ápice se utilizó una fresa redonda de carburo de tungsteno, realizando la resección apical con terminación biselada necesaria. Una vez seccionado el ápice radicular, se lavó la cavidad con gasas húmeda. La obturación retrógrada se finalizó con la aplicación del MTA en la caja retrógrada, eliminando el exceso de material (Figura 5,6). Como procedimiento final se colocó un injerto óseo bovino cubierto por una membrana reabsorbible con el fin de conseguir una mejor regeneración ósea con puntos aislados de ácido poliglicólico 4-0. Se afrontaron los tejidos, sin complicaciones posoperatorias (Figura 7,8,9).

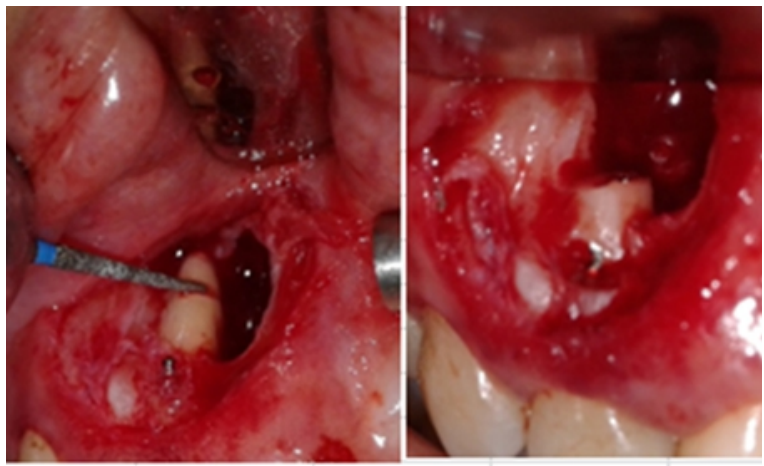

Figura 5-6. Apisectomia y desgaste de perno perforado Fuente: Elaboración propia

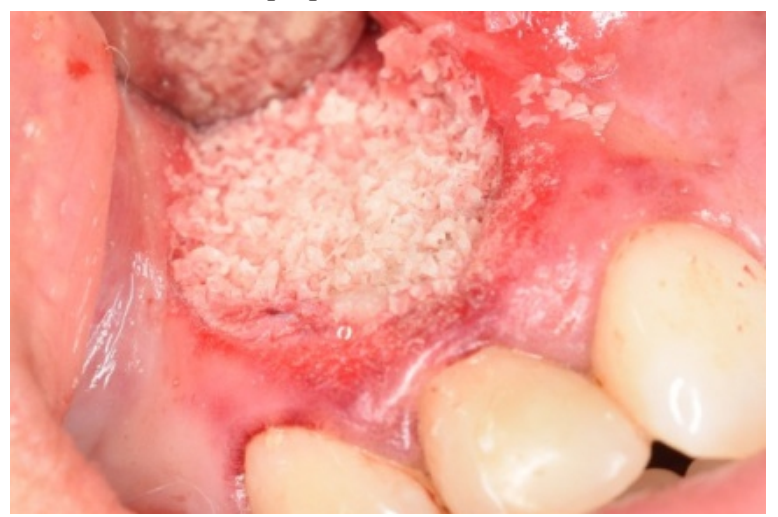

Figura 7. Sellado con MTA de membrana Fuente: Elaboración propia

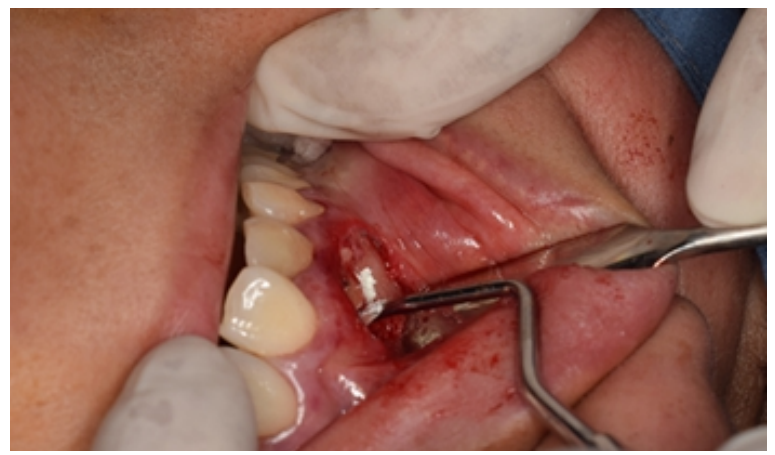

Figura 8. Relleno óseo y colocación de membrana Fuente: Elaboración propia 


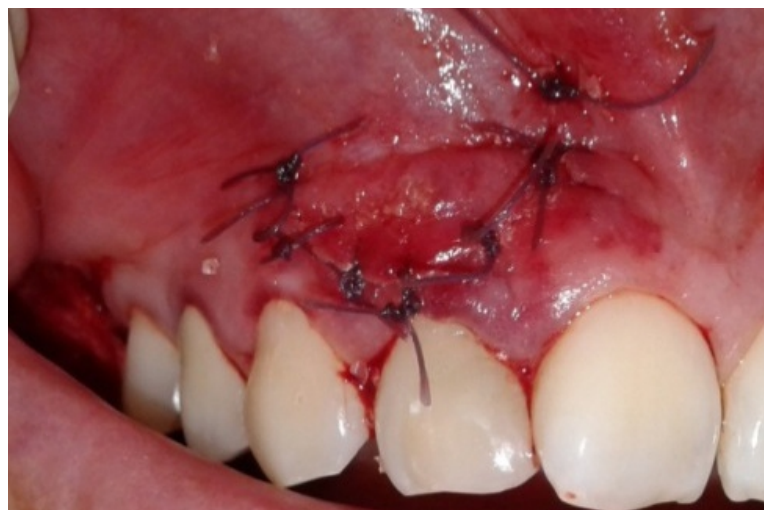

Figura 9. Sutura

Fuente: Elaboración propia

\section{Seguimiento Clínico}

El paciente evolucionó favorablemente después del procedimiento quirúrgico, y durante los meses posteriores no se presentaron nuevos abscesos en la zona intervenida. A los 6 meses del tratamiento quirúrgico, se obtuvo una imagen radiográfica del sitio de la lesión, la cual muestra evidencias de reparación ósea (Figura 10).

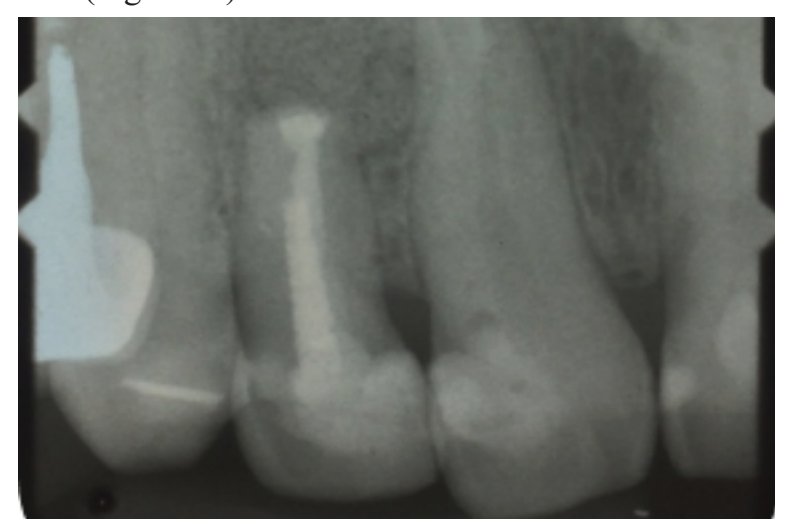

Figura 10. Control Posoperatorio 6 meses Fuente: Elaboración propia

\section{DISCUSIÓN}

El éxito o fracaso del tratamiento de una perforación radicular depende de que la infección bacteriana en el sitio de la perforación pueda ser prevenida o eliminada. Existe un número de factores que potencialmente pueden influir en el control de la infección en el lugar de la perforación: el tiempo transcurrido hasta su diagnóstico, el tamaño y forma de la perforación, así como su localización. Varios estudios experimentales demuestran que las perforaciones de larga data, extensas y con comunicación con el medio bucal son de peor pronóstico ${ }^{(5)}$.

La intervención quirúrgica en las perforaciones radiculares está indicada cuando estas son muy extensas o cuando ocurren como resultado de una reabsorción radicular. El propósito del tratamiento quirúrgico es lograr un sellado permanente e impermeable que prevenga la entrada de bacterias y sus productos del tejido periodontal ${ }^{(6)}$.

La realización de una apisectomía y la posterior obturación de la misma con un material de obturación apical está indicada para conseguir un buen sellado apical, y así prevenir la penetración de irritantes desde el conducto a los tejidos perirradiculares, y viceversa. Varios materiales como amalgama, IRM, Super EBA por mencionar algunos- han sido usados como materiales de obturación a retro ${ }^{(7)}$. A través de estudios in vivo se ha demostrado que el MTA se asocia a una menor inflamación de los tejidos adyacentes, una formación de cemento adyacente al MTA, y una buena regeneración de los tejidos perirradiculares ${ }^{(8)}$.

A pesar de existir varios elementos que atentan contra el éxito y hacen muy reservado el pronóstico de estos casos, como la extensión de las perforación y la segregación de la infección hacia los tejidos perriradicuales, la decisión de realizar el tratamiento quirúrgico fue acertada y su resultado fue exitoso porque se logró preservar de manera funcional y estética el diente afectado. 


\section{REFERENCIAS BIBLIOGRÁFICAS}

1. Farzaneh M, Abitbol S, Friedman S. Treatment outcomes in endodontics: the Toronto study. Phases I and II: orthograde retreatment. J Endod. 2004 [citado 13 dic 2012]; 30: 627-33.

2. Miñaga Gomez, M. El Agregado de Trióxido Mineral (MTA) en Endodoncia. (2002) RCOE, vol.7, no.3, p.283-289.

3. Miñaga Gomez, M. El Agregado de Trióxido Mineral (MTA) en Endodoncia. (2002) RCOE, vol.7, no.3, p.283-289.

4. Schartz S. Richard, et al. Mineral trioxide Aggregate: a new material for endodontics. (1999) JADA, Alaska, USA, 130(7):967-75.

Correspondencia:

Guiselle Andrea Verástegui Baldárrago andrea_gis_4@hotmail.com
5. Torabinejad M, Hong CU, Pitt Ford TR. Physical properties of a new root end filling material. (1995) J Endodon; 21: 34953.

6. Tsesis I, Fuss Z. Diagnosis and treatment of accidental root perforations. Endodontic Topics. 2006 ; 13(1): 5-107. Disponible en:

http://onlinelibrary.wiley.com/doi/10.1111/j.16011546.2006.00213.x/abstract

7. Torabinejad M, Pitt Ford TR, McKendry DJ, Abedi HR, Miller DA, Kariyawasem SP. Histologic assessment of MTA as root end filling in monkeys. J Endodon 1997; 23; 225-8.

8. Torabinejad M, Hong CU, Lee SJ, Monsef M, Pitt Ford TR. Investigation of mineral trioxide aggregate for root-end filling in dogs. J Endodon 1995; 21:603-8.

Fecha de recepción : 02 de enero de 2019

Fecha de aceptación : 07 de mayo de 2019 